\title{
One-step individual patient data (IPD) network meta-analysis of survival data using royston- parmar models
}

\author{
Suzanne Freeman ${ }^{1 *}$, James Carpenter ${ }^{1,2}$, Jayne Tierney ${ }^{1}$ \\ From 3rd International Clinical Trials Methodology Conference \\ Glasgow, UK. 16-17 November 2015
}

\section{Background}

Network meta-analysis (NMA) combines direct and indirect evidence from trials to calculate treatment effect estimates and rank treatments. Modelling approaches for continuous and binary outcomes are relatively well developed, but less work has been done with time-toevent outcomes. Such outcomes have usually been analysed using Cox proportional hazard ( $\mathrm{PH}$ ) models, but in oncology with longer follow-up of trials, and timedependent effects of targeted treatments, this may no longer be appropriate. Royston-Parmar models, fitted using WinBUGS, are a flexible alternative.

\section{Methods}

Motivated by IPD from 39 trials comparing combinations of surgery, radiotherapy and chemotherapy from 7636 women with cervical cancer (3184 events), we developed an IPD Royston-Parmar NMA model for overall and disease-free survival. We fitted this model in one-step using WinBUGS. By including a treatment-log(time) interaction we were able to test for PH. Extensions allowed for covariate and treatment-covariate interactions.

\section{Results}

A global test of PH showed it to be a reasonable assumption for these data. A joint test of the treatment-cancer stage interaction was significant. This was principally due to the differential effectiveness of chemoradiation versus radiotherapy by cancer stage at randomisation. The overall network-heterogeneity Q statistic was not significant, but there was evidence of moderate heterogeneity within one of the designs.

${ }^{1}$ MRC Clinical Trials Unit at UCL, London, UK

Full list of author information is available at the end of the article

\section{Conclusion}

Our approach provides a range of flexible models for one-step NMA of IPD survival data. It naturally handles missing covariate data. A practically important advantage is that the underlying Royston-Parmar model allows the approach to extend readily to handle non- $\mathrm{PH}$ in both treatment and treatment-covariate interactions.

\section{Authors' details}

'MRC Clinical Trials Unit at UCL, London, UK. 'London School of Hygiene \& Tropical Medicine, London, UK.

Published: 16 November 2015

doi:10.1186/1745-6215-16-S2-P161

Cite this article as: Freeman et al:: One-step individual patient data (IPD) network meta-analysis of survival data using royston-parmar models. Trials 2015 16(Suppl 2):P161.
Submit your next manuscript to BioMed Central and take full advantage of:

- Convenient online submission

- Thorough peer review

- No space constraints or color figure charges

- Immediate publication on acceptance

- Inclusion in PubMed, CAS, Scopus and Google Scholar

- Research which is freely available for redistribution
C Biomed Central 